RESTOR 00014

\title{
B-50/GAP-43 in neuronal development and repair
}

\author{
W. H. Gispen ${ }^{1}$, J. Boonstra ${ }^{1}$, P. N. E. De Graan ${ }^{1}$, F. G. I. Jennekens ${ }^{1}$, \\ A. B. Oestreicher ${ }^{1}$, P. Schotman ${ }^{1}$, L. H. Schrama ${ }^{1}$, J. Verhaagen ${ }^{2}$ and \\ F. L. Margolis ${ }^{2}$
}

\begin{abstract}
${ }^{1}$ Division of Molecular Neurobiology, Rudolf Magnus Institute and Institute of Molecular biology, University of Utrecht, Utrecht (The Netherlands) and ${ }^{2}$ Department of Neurosciences, Roche Institute of Molecular Biology, Nutley, NJ (U.S.A.)
\end{abstract}

(Accepted 26 September 1989)

Key words: B-50/GAP-43; Axonal regeneration; Neuronal development; Sciatic nerve; Pyramidal tract; Olfactory system; Melanocortins; Protein kinase C

\begin{abstract}
The protein kinase C substrate B-50 is identical to the growth-associated protein GAP-43. Although as yet no causal relationship has been established between B-50/GAP-43 and neurite outgrowth, evidence accumulates that the function of the protein relates to neuronal plasticity. Stimulation of PC12 cells by NGF results in translocation of the protein from cytosolic stores to the membrane of newly formed neurite-like extensions. The protein is associated with the inner leaflet of the growth cone membrane isolated from neonatal rat brain and was used as a marker to study the development of the rat pyramidical tract and olfactory system. In the adult rat, crush lesion of the sciatic nerve results in a rapid expression of B-50/GAP-43 mRNA followed by synthesis of B-50/GAP-43 protein in dorsal root ganglia and transport of the protein into the newly formed sprouts. Presumably, the neurotrophic effect of melanocortins on peripheral nerve repair is not brought about by enhancement of B-50/GAP-43 synthesis per se. Bulbectomy (central) or Triton X-100 lesioning (peripheral) of the olfactory epithelium results in a differential expression of B-50/GAP-43 and the olfactory marker protein characterizing two stages in the regeneration of this epithelium. Evidence that the degree of phosphorylation may co-determine the role of B-50/GAP-43 in neurite outgrowth is discussed.
\end{abstract}

\section{Introduction}

In the early seventies two groups of investigators reported that in rodents brief behavioral experience induced specific changes in synaptic plasma membrane protein phosphorylation [23,44]. These studies inspired a series of experiments on the effect of behavioral active ACTH fragments of the phosphorylation of rat brain synaptosomal plasma membrane proteins. Surprisingly, in in-vitro studies $\mathrm{ACTH}_{1-24}$ inhibited the phos-

\footnotetext{
Paper presented at the Symposium on 'Regulators of Peripheral Nerve Regeneration', held in Ystad, Sweden, 6-8 July, 1989. Correspondence: W.H. Gispen, Rudolf Magnus Institute, Vondellaan 6, 3521 GD Utrecht, The Netherlands.
}

phorylation of specific relatively low molecular weight protein bands. These bands were different from those affected by cyclic AMP-dependent kinases [69]. In 1978, we reported for the first time on the ACTHsensitive synaptic phosphoprotein termed B-50 [68,70], followed in 1980 by the purification and amino-acid composition of this protein and its endogenous ACTHsensitive B-50 kinase $[71,72]$. We concentrated on the significance of the degree of phosphorylation of the protein to neuronal membrane processes. It was established that the endogenous B-50 kinase was identical to protein kinase C (PKC) [2,3]. Furthermore it was observed that changes in the degree of phosphorylation negatively correlated with the phosphorylation of phosphatidylinositol 4-phosphate (PIP) to phosphatidylinositol 4,5-biphosphate $\left(\mathrm{PIP}_{2}\right)$ [33,34]. These studies 
presumably linked the protein B-50 to receptormediated transmembrane signal transduction. For, activation of certain receptors would lead to hydrolysis of $\mathrm{PIP}_{2}$ yielding inositol triphosphate (calcium mobilization) and diacylglycerol stimulating PKC (see for instance [1]). Based on the results obtained by $\mathrm{Van}$ Dongen et al. [54] we postulated that receptormediated hydrolysis of PIP $_{2}$ would lead to enhanced B-50 phosphorylation and inhibition of PIP-kinase activity thus providing the membrane with a negative feedback control over the availability of $\mathrm{PIP}_{2}$ for further receptor-activated hydrolysis [20].

Meanwhile, it became apparent that what we studied as B-50 was a protein similar if not identical to what was known otherwise as F1, GAP-43, pp46 or the calmodulin binding protein P-57 (see for review [5,49]). The notion that perhaps B-50 belonged to the so-called growth-associated proteins (GAP) prompted us to study the protein also in that context. In this manuscript we will briefly review some of our evidence, which confirms and extends the significance of B-50/GAP-43 for neuronal development and repair.

\section{B-50/GAP-43 and neurite formation}

\section{B-50/GAP-43 and NGF-induced differentiation of rat pheochromocytoma cells $\mathrm{PCl} 2$}

Exposure of PC12 cells to nerve growth factor (NGF) results in the arrest of cell growth and induction of differentiation to sympathetic neuron-like cells, bearing neurite-like extensions [28]. Hence the PC12 cell line is a suitable model to study molecular and cellular aspects of neurite formation and outgrowth. In the first study we identified a $48-\mathrm{kDa}$ phosphoprotein as the neuron-specific PKC substrate B-50/GAP-43 on basis of comigration with purified B-50/GAP-43, immunoreactivity and phosphopeptide mapping [55]. B-50/GAP-43 is present in both undifferentiated and NGF-treated PC12 cells. Exposure of PC12 cells to NGF $(48 \mathrm{~h} ; 100 \mu \mathrm{g} 7 \mathrm{~S} / \mathrm{ml})$ increased the amount of B-50 by 2.5 -fold as measured by radioimmunoassay (from 36 to $90 \mathrm{ng}$ B-50/GAP-43/mg protein) [55], presumably as a result of NGF-induced induction of B-50/GAP-43 mRNA in these cells $[4,35]$. Immunofluorescence microscopy revealed that B-50/GAP-43 is mainly localized at the cell membrane and in growth cones [55].

Recently we reported the ultrastructural localization of the protein in PC12 cells before and after NGF- or dibutyryl cyclic AMP-induced differentiation [57]. B-50/GAP-43 immunogold labeling of cryo-sections of untreated PC12 cells is mainly associated with lysosomal structures, including multivesicular bodies, second- ary lysosomes and Golgi apparatus. Notably, the plasma membrane is virtually devoid of label. However, after $48 \mathrm{~h}$ of treatment of the cells with NGF, B-50/GAP-43 immunoreactivity is most pronounced on the plasma membrane. Highest B-50/GAP-43 immunoreactivity is observed at plasma membranes surrounding sprouting microvilli, lamellipodia and filopodia. Outgrowing neurites display a scattered B-50/GAP-43 labeling, which is partly associated with chromaffin granules. Interestingly, although differences between NGF- and cyclic AMP-induced neurite formation in PC12 cells have been reported [61] the B-50/GAP-43 distribution in cyclic AMP-differentiated cells closely resembled that seen in NGF-treated cells. Thus, both differentiating procedures resulted in a marked shift in the ultrastructural localization of B-50/GAP-43 from cytosolic compartments to the innerside of the plasma membrane. This translocation accompanies the acquisition of neuronal features of PC12 cells and again points to a neurite growthassociated role for $\mathrm{B}-50 / \mathrm{GAP}-43$ performed at the plasma membrane at the site of protrusion or in the growth cone [57]. Thus, if B-50/GAP-43 has a specific role in neurite growth, most likely it must function in a membrane-associated process such as signal transduction or membrane extension (see below; $[22,49]$ ).

\section{Growth cones}

Since Ramon y Cajal first described the bulbous leading top of growing axons as 'cone de croissance', much attention has been focused on the role of these growth cones in leading extending neurites to their appropriate targets. On its path the growth cone meets a spectrum of extracellular signals and cues that contribute to the strength of its adhesion, its morphological appearance, the direction and selectivity of its movements and thereby to the synaptic architecture of the mature nervous system. It may well be that the growthassociated nature of $\mathrm{B}-50 / \mathrm{GAP}-43$ relates to a regulating role in the processes that govern growth cone mobility (see also [58]). An ultrastructural immunocytochemical study on B-50/GAP-43 localization in growth cones isolated from neonatal rat brains was carried out by means of cryo-ultramicrotomy with affinity-purified anti-B-50/GAP-43 immunoglobulins and immunogold detection [60]. The majority of the B-50/GAP-43 was detected at the plasma membrane with a small fraction in the cytoplasm not evidently associated with internal membranes. The data indicate that in the growth cone of rat brain neurons B-50/GAP-43 is mainly located at the cytoplasmic face of the plasma membrane [60]. Indeed, B-50/GAP-43 appeared to be a major phosphoprotein in membranes 
prepared from subcellular fetal brain homogenates enriched in growth cones. In analogy to the situation in the synaptic plasma membranes isolated from adult brain tissue, in the growth cone membrane the protein is a predominant substrate to PKC $[12,56]$. Interestingly, also in the growth cone membrane there seems to exist an inverse relationship between the phosphorylation of B-50/GAP-43 and the activity of PIP-kinase. Therefore it was suggested that the phosphorylation of B-50/GAP-43 may be an important factor in signal transduction through the growth cone membrane $[56,58]$. In view of the complexity of the interaction between the nerve growth cone and its exterior milieu, proteins that provide regulating control may play a key role in axonal growth.

Membrane depolarization and neurotransmitters are both presumed to modulate growth cone function and maturation of a growth cone into a synaptic terminal $[11,40]$. Furthermore, it was shown that the local intracellular calcium concentration, possibly affected by membrane depolarization or receptor activation, determined in a precise mode the behaviour and function of the growth cone [36]. Hence, we studied the effect of membrane depolarization $\left(30 \mathrm{mMK}^{+}\right)$and neurotransmitter action (acetylcholine) on the degree of phosphorylation of B-50/GAP-43 in growth cones prelabeled with $\left[{ }^{32} \mathrm{P}\right]$ orthophosphate. Depolarization induced by $30 \mathrm{mM} \mathrm{K} \mathrm{K}^{+}$produced a transient rapid increase in B-50/GAP-43 phosphorylation via stimulation of PKC. Also cholinergic receptor activation by carbachol enhances B-50/GAP-43 phosphorylation in a dose-dependent manner. Both the depolarizationand the cholinergic activation-induced effects on B-50/GAP-43 phosphorylation could be inhibited by incubation with atropine [59]. These data served as first indication that B-50/GAP-43 phosphorylation in growth cones may be affected in a receptor-mediated manner. Such data support the working hypothesis that phosphorylation of B-50/GAP-43 by PKC mediates signal transduction in nerve growth cones.

In line with the ultrastructural and biochemical evidence are data to suggest a relative enrichment of B-50/GAP-43 in the peripheral neurite segments of dorsal root ganglion (DRG) in culture as that is the region enriched in growth cones $[41,45]$. In fact, around the explanted ganglion itself there is a rather light halo indicating little if any B-50/GAP-43 immunoreactivity in the proximal neurite segments. The protein is transported by rapid axonal transport $[47,49]$ and incubation of DRGs in the presence of the transport blocker colchine leads to a decrease in total amount of B-50/GAP-43 (radioimmunoassay) and a marked redistribution within the neurons [45]. The low- intensity halo of B-50/GAP-43 staining disappeared and now cell bodies of neurons migrating from the explanted DRG into the newly formed neurite network were found to be heavily stained for B-50/GAP-43. Indirectly these data confirm and extend that under normal conditions B-50/GAP-43 is synthesized in the neuronal cell body and transported rapidly towards the growth cone.

\section{B-50/GAP-43 as a marker for developmental neural plasticity}

Although there is some question about the neuronspecific nature of B-50/GAP-43 [67] to date the vast majority of the data point to an age-related expression of this protein exclusively in neurons [49]. Highly expressed during development in some neurons its expression is repressed during adulthood, in others it markedly declines with age [43]. Its unique localization in the growth cone membrane makes it a very useful marker of the establishment of neuronal networks in the nervous system.

\section{Pyramidal tract and neuromuscular junction}

The ontogenesis of the spinal pyramidal tract in the rat occurs during the postnatal development. Shortly after birth, the leading corticospinal fibres are entering the upper cervical segments of the spinal cord [46], where they occupy the most ventral part of the dorsal funiculus. Gribnau et al. [29] demonstrated that the corticospinal fibres have reached the upper thoracal segments of the spinal cord at postnatal day $2\left(\mathrm{P}_{2}\right)$ and the sacral segments at $\mathrm{P}_{7}$. A delay of 2 days was observed between the arrival of the corticospinal axons at a given spinal cord level and their outgrowth into the adjacent spinal gray. Indeed, electron-microscopic analysis revealed the presence of numerous growth cones in the growth zone of the developing pyramidical tract [17]. To document the relation between the expression of B-50/GAP-43 and the outgrowth of central axons, we studied B-50/GAP-43 in the developing pyramidical tract in rats at postnatal day $\mathrm{P}_{2}, \mathrm{P}_{7}$ and $\mathrm{P}_{90}$ at the third cervical segment $\mathrm{C}_{3}$, using affinity-purified anti-B-50/GAP-43 immunoglobulins. At $\mathrm{P}_{2}$ and $\mathrm{P}_{7}$, when outgrowth of pyramidical tract fibres is occurring, B-50/GAP-43 staining is intense in these fibres. In the ascending fibres of the tractus cuneatus and gracilis, which develop earlier, there is a significant drop in staining intensity from $\mathrm{P}_{2}$ to $\mathrm{P}_{7}$. At $\mathrm{P}_{90}$ when most of the dorsal funiculus fibres have reached their targets and many are myelinated, B-50/GAP-43 staining is dramatically reduced (as measured by radioimmunoassay a 10 -fold decrease at $\mathrm{P}_{90}$ as compared to $\mathrm{P}_{7}$ [24]). 
Immuno-electron microscopy confirmed these findings and revealed that in the adult pyramidal tract still both some myelinated and unmyelinated axons continue to contain the B-50/GAP-43 protein [25].

In a recent study we investigated the expression of B-50/GAP-43 in the human peripheral nervous system as a function of age [31]. By means of immunofluorescence and electron microscopy it was demonstrated that in the lower limb or intracostal muscles nearly all fetal endplates were immunoreactive for B-50/GAP-43. Apparently also in the human nervous system the expression of B-50/GAP-43 is developmentally regulated, as the percentage of $\mathrm{B}-50 / \mathrm{GAP}-43$ positive endplates decreases during the peri- and postnatal periods. In children and adults a low percentage of B-50/GAP-43 positive endplates remain present [31]. Evidence indicating on-going remodeling in neuromuscular junctions throughout life has been obtained in studies of animal endplates [8] and thus may explain the persistence of some endplates B-50/GAP-43 positive endplates throughout life $[64,31]$.

\section{Olfactory system}

The olfactory epithelium has the unique ability to generate new neurons from a population of precursor cells present in the basal layer of the neuroepithelium. Division and differentiation of these precursor cells occur throughout life in all vertebrates examined [27]. The specific molecular events that underlie the exceptional neurogenic capacity of the olfactory receptor cell precursors are largely unknown. However, maturation of the olfactory neuroepithelium is paralleled by a progressive increase in the number of neurons containing the olfactory marker protein (OMP; [38]) and expressing olfactory cilia [9]. Apparently, OMP is only expressed in olfactory neurons that have reached a relatively advanced state of maturation. We used polyclonal anti-OMP and anti-B-50/GAP-43 immunoglobulins to gain insight in the dynamics of the olfactory epithelium during postnatal development and in adult rat assuming that the B-50/GAP-43 antibodies would stain immature differentiating and anti-OMP antibodies mature olfactory neurons [66]. In newborn rats B-50/GAP-43 is present throughout the entire population of olfactory receptor neurons. These cells are stained throughout, from the ciliated dendritic knob to their axon terminals in the bulb. This appears to be the first example of unambiguous B-50/GAP-43 expression in dendritic processes and thus questions the generality of the suggestion put forward by Goslin et al. [26] that B-50/GAP-43 specifically would label differentiating axons and not dendrites. With increasing age the dis- tribution of B-50/GAP-43 becomes progressively restricted to a subpopulation of olfactory neurons. Comparing the expression of B-50/GAP-43 to that of OMP during postnatal development, revealed that the two proteins are indeed expressed in a nearly reciprocal fashion. In adult animals, B-50/GAP-43 positive cells are exclusively present adjacent to the basal cell layer of the neuroepithelium. The basal precursor cells themselves, however, appear to be unstained. The region of the epithelium containing the B-50/GAP-43-positive cells is virtually devoid of OMP-containing olfactory neurons. A significant fraction of these B-50/ GAP-43-positive cells bear dendritic and neuritic processes but lack olfactory cilia. Most likely the olfactory neurons that express the growth-associated B-50/GAP-43 protein correspond to a particular subset of olfactory neurons at an intermediate state of maturation [66].

\section{B-50/GAP-43 expression during postlesion repair}

\section{Peripheral nervous system}

The initial studies of Skene and Willard [47] using metabolic labeling lead to the identification of several GAPs including B-50/GAP-43. Verhaagen et al. [62] confirmed and extended these observations using immunoblotting, radioimmunoassay and immunohistochemistry of B-50/GAP-43 in the crushed sciatic nerve in the rat. Virtually no B-50/GAP-43 immunoreactivity was seen in control nerves, but bright immunofluorescence appeared in regenerating sprouts. B-50/GAP-43 levels in the crushed nerve increased 5.3-fold as compared to non-crushed controls [62]. Normal neuromuscular junctions of the soleus muscle, one of the target muscles of the sciatic nerve, only rarely contained B-50/GAP-43, but during the period of reinnervation following sciatic nerve damage, neuromuscular junctions contained abundant amounts of B-50/GAP-43. After completion of the reinnervation the B-50/GAP-43 levels returned to control [64]. Furthermore we noted a peculiar transient increase in the percentage of B-50/GAP-43 immunoreactive neuromuscular junctions during the first 2 days after denervation. This phenomenon could not easily be related to the reinnervation process [64]. Tetzlaff et al. [52] determined the axonal transport and localization of B-50/GAP-43-like immunoreactivity in regenerating rat sciatic nerves. They reported the remarkable observation that midway between the position of the crush and the fastest-growing axons, B-50/GAP-43 immunoreactivity was associated with Schwann cell profiles of the bands of Bunger. It was concluded that perhaps B-50/GAP-43 might be secreted from regenerating 
axons in order to reach the Schwann cell membranes or adjacent basal laminae, pointing to yet new options for a role of B-50/GAP-43 in nerve regeneration [52].

In a more recent series of experiments we studied the time-course of the B-50/GAP-43 mRNA expression in rat DRG following crush lesioning of the sciatic nerve [53]. The specific hybridization signal of a B-50/ GAP-43 cRNA probe with one mRNA band $(1.5 \mathrm{~kb})$ was quantified by image analysis. Between 8 and $16 \mathrm{~h}$ after placement of the crush a rise in B-50/ GAP-43 mRNA took place; a linear increase up to 10 times the basal level of B-50/GAP-43 mRNA up to 2 days postsurgery was observed. Then, the B-50/ GAP-43 mRNA level declined rather slowly to normal levels at approximately day 37 postsurgery. Under similar conditions Basi et al. [4] reported at one time point (14 days postoperation) a rise of one order of magnitude. Hoffman [32] demonstrated that in addition to B-50/GAP-43 mRNA expression there is also a rise in $\beta$-tubulin mRNA expression during postlesion repair of the sciatic nerve. It is expected that structural proteins required for the sprouting and regulation of damaged axons will be expressed in concert following nerve damage. From the existence of one single gene for B-50/GAP-43 and the concomitant changes in the levels of mRNA and protein it has been suggested that the regulation of the expression of B-50/GAP-43 occurs mainly at the transcriptional level [4], although during the later phase of regeneration the persistence of high levels of B-50/GAP-43 may relate to changes in the half life of the protein at the (post)translational level [53].

It is generally believed that precise knowledge concerning the molecular processes that govern axonal repair will open new perspectives to develop new therapies for the cure of hitherto seemingly incurable degenerative diseases of the nervous system [18]. It may be that insight into the growth-associated function of B-50/GAP-43 may be of significance in this respect. Hence we tested whether the known neurotrophic action of peptides derived from ACTH/MSH [51,21] might involve specific enhancement of B-50/GAP-43 expression in the damaged nerve. Previously it was shown by a variety of investigators that ACTH/ MSH-like peptides among which the synthetic $\mathrm{ACTH}_{4-9}$ analog Org 2766 facilitated recovery of sensorimotor function following a crush lesion of the rat sciatic nerve $[6,14,50]$. The precise mechanism of action of these peptides is not understood. It may be that exogenously administered peptides mimic or amplify an endogenous pathophysiological peptide signal early in the repair process either formed in the distal portion of the crushed nerve [17] or in the cell bodies of the altered neurons [30]. The peptides enhance the nerve repair by increasing the number of outgrowing myelinated and unmyelinated sprouts $[7,63]$ and not by enhancing the speed of their elongation [15,19]. Hence we wondered whether the peptide treatment would enhance the sprouting response by stimulating the B-50/GAP-43 production. Treatment with Org 2766 did indeed further enhance the amount of B-50/GAP-43 in crushed sciatic nerves, however, the increase was proportional to the peptide-induced increase in newly formed sprouts $[53,63]$. Hence it was concluded that most likely the higher level of B-50/GAP-43 in the peptide-treated crushed nerve was merely a reflection of the higher number of B-50 containing new sprouts and not specifically related to the peptide action per se. Further work is in progress to address this point more fully.

\section{Olfactory system}

As discussed above, in the olfactory neuroepithelium neurogenesis can occur throughout life and is essential for the replacement of mature olfactory neurons that degenerate in response to noxious environmental stimuli or recovery from trauma damaging the first cranial nerve. This makes the olfactory system attractive for the study of postlesion neuronal repair mechanisms. The regeneration of the olfactory neuroepithelium following lesioning was studied with mRNA probes and antibodies for B-50/GAP-43 and OMP [65]. Two stages in the regeneration of the olfactory epithelium could be discerned. The first stage occurs following either peripheral lesioning of the olfactory epithelium with Triton $\mathrm{X}-100$ or after bulbectomy and is characterized by the formation of a large population of immature olfactory receptor neurons. These newly formed neurons could be identified by virtue of their expression of B-50/GAP-43. During the second stage of the regeneration process the newly formed olfactory neurons mature as manifested by a decrease in B-50/GAP-43 and an increase in the expression of OMP. The formation of a full complement of OMP expressing neurons, a characteristic feature of the second stage of olfactory nerve regeneration, occurs only after peripheral Triton X-100 lesioning. Following bulbectomy the reconstituted olfactory epithelium is arrested in its ability to recover from nerve damage as evidenced by a large number of B-50/GAP-43 expressing neurons up to 3 months after the lesion. Monti-Graziadei [42] proposed that the increased neurogenic activity in the olfactory epithelium during the first week following bulbectomy results in the continuous formation of new neurons that begin to mature, but then die because they are unable to form a synaptic contact as the bulb had been removed. Our current data on the differential 
expression of B-50/GAP-43 and OMP distinguishing between immature and mature phenotypes of olfactory neurons confirm the important role of the bulb in permitting full maturation of the olfactory neuroepithelium [65].

\section{Conclusion}

In the present short survey we have summarized our contribution to the understanding of the function of B-50/GAP-43 to neuronal maturation and postlesion repair. The precise function or mechanism of action of B-50/GAP-43 in developing, regenerating and adult peripheral and central nervous system neurons is still not elucidated. The recognition that the protein is a substrate for PKC and that the phosphorylation reduced its ability to bind calmodulin, puts the protein in the midst of transmembrane signal transduction mechanisms [22]. In the developing/regenerating neuron the axonal growth cone enriched in B-50/GAP-43 may be in need of the protein either as a buffer of calmodulin or as regulator in the polyphosphoinositide response to external signals that guide its motility. In the adult presynaptic terminal modulation of its phosphorylation may have consequences for synaptic plasticity as evidenced by correlative phosphorylation changes in B-50/GAP-43 during long-term potentiation [5] and neurotransmitter release [13].

\section{References}

1 Agranoff, B. W. and Fisher, S. K., Ligand-stimulated turnover of inositol lipid in the nervous system, Progr. Brain Res., 69 (1986) $3-15$.

2 Aloyo, V. J., Zwiers, H. and Gispen, W. H., B-50 protein kinase and kinase C in rat brain, Progr. Brain Res., 56 (1982) 303-315.

3 Aloyo, V. J., Zwiers, H. and Gispen, W. H., Phosphorylation of B-50 protein by calcium-activated, phospholipid-dependent protein kinase and B-50 protein kinase, J. Neurochem., 41 (1983) 649-653.

4 Basi, G. S., Jacobson, R. D., Virag, I., Schilling, J. and Skene, J. H. P., Primary structure and transcriptional regulation of GAP-43, a protein associated with nerve growth, Cell, 49 (1987) 785-791.

5 Benowitz, L. I. and Routtenberg, A., A membrane phosphoprotein associated with neural development, axonal regeneration, phospholipid metabolism and synaptic plasticity, Trends Neurosci., 10 (1987) 527-532.

6 Bijlsma, W. A., Jennekens, F. G. I., Schotman, P. and Gispen, W. H., Effects of corticotrophin (ACTH) on recovery of sensorimotor function in the rat: structural-activity study, Eur.J. Pharmacol., 76 (1981) 73-79.

7 Bijlsma, W. A., Van Asselt, E., Veldman, H., Jennekens, F. G. I., Schotman, P. and Gispen, W. H., Ultrastructural study of the effect of ACTH(4-10) on nerve regeneration: axons become larger in number and smaller in diameter, Acta Neuropathol., 62 (1983) 24-30.
8 Cardasis, C.A., Ultrastructural evidence of continued reorganization at the aging (11-26 months) rat soleus neuromuscular junction, Anat. Rec., 207 (1983) 399-415.

9 Chuah, M. I., Farbman, A. I. and Menco, B. Ph. M., Influence of olfactory bulb on dendritic knob density of rat olfactory receptor neurons in vitro, Brain Res., 338 (1985) 259-266.

10 Cimler, B. M., Giebelhaus, D. H., Wakin, B. T., Storm, D. R. and Moon, R. T., Characterization of murine cDNAs encoding P-57, a neural-specific calmodulin-binding protein, J. Biol. Chem., 262 (1987) 12158-12163.

11 Cohan, C. S., Connor, J. A. and Kater, S. B., Electrically and chemically mediated increases in intracellular calcium in neuronal growth cones, J. Neurosci., 7 (1987) 3588-3599.

12 De Graan, P. N. E., Van Hooff, C. O. M., Tilly, B. C., Oestreicher, A. B., Schotman, P. and Gispen W. H., Phosphoprotein B-50 in nerve growth cones from fetal rat brain, Neurosci. Lett., 61 (1985) 235-241.

13 De Graan, P. N. E., Schrama, L. H., De Wit, M., Oestreicher, A. B. and Gispen,W. H., Carbachol-induced changes in the phosphorylation of growth-associated protein kinase $\mathrm{C}$ substrate B-50 (GAP-43) in neuronal growth cones, Meeting Soc. Neurosci., Phoenix, U.S.A., 1989, Abstract.

14 Dekker, A. J. A. M., Princen, M. M., De Nijs, H., De Leede, L. G. J. and Broekkamp, C. L. E., Acceleration of recovery from sciatic nerve damage by the ACTH(4-9) analog Org. 2766; different routes of administration, Peptides, 8 (1987) 1057-1059.

15 De Koning, P., Brakkee, J. H. and Gispen, W. H., Methods for producing a reproducible crush in the sciatic and tibial nerve of the rat and rapid and precise testing of return of sensory function: beneficial effects of melanocortins, J. Neurol. Sci., 74 (1986) 237-246.

16 De Kort, E. J. M., Gribnau, A. A. M., Van Aanholt, H. T. H. and Nieuwenhuys, R., On the development of the pyramidal tract in the rat. I. The morphology of the growth zone, Anat. Embryol., 172 (1985) 195-204.

17 Edwards, P. M. and Gispen, W. H., Melanocortin peptides and neural plasticity. In J. Traber and W. H. Gispen (Eds.), Senile Dementia of the Alzheimer's Type: Early Diagnosis, Neuropathology and Animal Models, Springer-Verlag, Heidelberg, 1985, pp. 231-240.

18 Gelijns, A. C., Graaff, P. J., Lopes da Silva, F. H. and Gispen, W. H., Future health care applications resulting from progress in the neurosciences: the significance of neural plasticity research, Health Policy, 8 (1987) 265-276.

19 Gerritsen van der Hoop, R., Brakkee, J. H., Kappelle, A., Samson, M., De Koning, P. and Gispen, W. H., A new approach for the evaluation of recovery after peripheral nerve damage, $J$. Neurosci. Methods, 26 (1988) 111-116.

20 Gispen, W. H., Phosphoprotein B-50 and phosphoinositides in brain synaptic plasma membranes: a possible feedback relationship, Trans. Biochem. Soc. U.K., 14 (1986) 163-165.

21 Gispen, W. H., De Koning, P., Kuiters, R. R. F., Van der Zee, C. E. E. M. and Verhaagen, J., On the neurotrophic action of melanocortins, Progr. Brain Res., 72 (1987) 319-331.

22 Gispen, W. H., De Graan, P. N. E., Oestreicher, A. B., Schotman, P. and Schrama, L. H., The protein kinase C substrate protein B-50 in neural signal transduction. In M. Ito and Y. Nishizuka (Eds.), Brain Signal Transduction and Memory, Academic Press, New York, in press.

23 Glassman, E., Gispen, W. H., Perumal, R., Machlus, B. and Wilson, J. E., The effect of short experiences on the incorporation of radioactive phosphate into synaptosomal and nonhistone acid-extractable nuclear proteins from rat and mouse 
brain, Proceedings 5th Int. Congr. Pharmacol., Vol. 4, Karger, Basel, 1973, pp. 14-17.

24 Gorgels, Th. G. M. F., Oestreicher, A. B., De Kort, E. J. M. and Gispen, W. H., Immunochemical distribution of the protein kinase C substrate B-50 (GAP-43) in developing rat pyramidal tract, Neurosci. Lett., 83 (1987) 59-64.

25 Gorgels, Th. G. M. F., Van Lookeren Campagne, M., Oestreicher, A. B., Gribnau, A. A. M. and Gispen, W. H., B-50/GAP-43 is localized at the cytoplasmic side of the plasma membrane in developing and adult rat pyramidal tract, $J$. Neurosci., in press.

26 Goslin, K., Schreyer, D. J., Skene, J. H. P. and Banker, G., Development of neuronal polarity: GAP-43 distinguishes axonal from dendritic growth cones, Nature, 336 (1988) 672-674.

27 Graziadei, P. P. C. and Monti Graziadei, G. A., The olfactory system: a model for the study of neurogenesis and axon regeneration in mammals. In C. W. Cotman (Ed.), Neuronal Plasticity, Raven Press, New York, 1978, pp. 53-72.

28 Greene, L. A. and Tischler, A. S., Establishment of a noradrenergic clonal line of rat adrenal pheochromocytoma cells which respond to nerve growth factor, Proc. Natl. Acad. Sci. U.S.A., 73 (1976) 2424-2428.

29 Gribnau, A. A. M., De Kort, E. J. M., Dederen, P. J. W. C. and Nieuwenhuys, R., On the development of the pyramidal tract in rat. II. An anterograde tracer study of the outgrowth of the corticospinal fibers, Anat. Embryol., 175 (1986) 101-110.

30 Haynes, L. W. and Smith, M. E., The regulation by $\beta$-endorphin and related peptides of collagen-tailed acetylcholinesterase forms in the skeletal muscles of vertebrates. In G. Stefano (Ed.), CRC Handbook of Comparative Aspects of Opioid and Related Neuropeptides Mechanisms, Vol. II, CRC Press, San Francisco, CA, 1986, pp. 65-79.

31 Hesselmans, L. F. G. M., Jennekens, F. G. I., Van den Oord, C. J. M., Oestreicher, A. B., Veldman, H. and Gispen, W. H., A light and electron microscopical study of B-50 (GAP-43) in human intramuscular nerve and neuromuscular junctions during development, J. Neurol. Sci., 89 (1989) 301-311.

32 Hoffman, P. N., Expression of GAP-43, a rapidly transported growth-associated protein, and class II beta tubulin, a slowly transported cytoskeletal protein, are coordinated in regenerating neurons, J. Neurosci., 9 (1989) 893-897.

33 Jolles, J., Zwiers, H., Van Dongen, C. J., Schotman, P. Wirtz, K. W. A. and Gispen, W. H., Modulation of brain polyphosphoinositide metabolism by ACTH-sensitive protein phosphorylation, Nature, 286 (1980) 623-625.

34 Jolles, J., Zwiers, H., Dekker, A., Wirtz, K. W. A. and Gispen, W. H., Corticotropin-(1-24)-tetracosapeptide affects protein phosphorylation and polyphosphoinositide metabolism in rat brain, Biochem. J., 194 (1981) 283-294.

35 Karns, L. R., Ng, S. C., Freeman, J. A. and Fishman, M. C., Cloning of complementary DNA for GAP-43, a neuronal growth-related protein, Science, 236 (1987) 597-600.

36 Kater, S. B., Mattson, M. P., Cohan, C. and Connor, J., Calcium regulation of the neuronal growth cone, Trends Neurosci., 11 (1988) 315-321.

37 Katz, F., Ellis, L. and Pfenninger, K. H., Nerve growth cones isolated from fetal rat brain. III. Calcium-dependent protein phosphorylation, J. Neurosci., 5 (1985) 1402-1411.

38 Margolis, F. L., A brain protein unique to olfactory bulb, Proc. Natl. Acad. Sci. U.S.A., 69 (1972) 1121-1224.

39 Margolis, F. L., Molecular cloning of olfactory specific gene products. In F. L. Margolis and T. V. Getchell (Eds.), Molecular Neurobiology of the Olfactory System, Plenum Press, New York, 1988 , pp. $237-265$
40 Mattson, M. P., Neurotransmitters in the regulation of neuronal cytoarchitecture, Brain Res. Rev., 13 (1988) 179-212.

41 Meiri, K. F., Pfenninger, K. H. and Willard, M. B., Growthassociated protein, GAP-43, a polypeptide that is induced when neurons extend axons, is a component of growth cones and corresponds to pp46, a major polypeptide of a subcellular fraction enriched in growth cones, Proc. Natl. Acad. Sci. U.S.A., 83 (1986) 3537-3541

42 Monti-Graziadei, G. A., Experimental studies on the olfactory marker protein. III. The olfactory marker protein in the olfactory neuroepithelium lacking connection with the forebrain, Brain Res., 262 (1983) 303-308.

43 Oestreicher, A. B., De Graan, P. N. E. and Gispen, W. H., Neuronal cell membranes and aging, Progr. Brain Res., 70 (1986) 239-254.

44 Routtenberg, A., Ehrlich, Y. and Rabjohns, R. R., Effect of a training experience on phosphorylation of a specific protein in neocortical and subcortical membrane preparations, Fed. Proc., 34 (1975) 293.

45 Schmidt-Michels, M., Edwards, P. M., Oestreicher, A. B. and Gispen, W. H., Colchicine effect on B-50 localization in rat dorsal root ganglion in culture, Neurosci. Lett., 97 (1989) 285-290.

46 Schreyer, D. J. and Jones, E. G., Growth and target finding by axons of the corticospinal tract in prenatal and postnatal rats, Neuroscience, 7 (1982) 1837-1853.

47 Skene, J. H. P. and Willard, M., Characteristics of growthassociated polypeptides in regenerating toad retinal ganglion cell axons, J. Neurosci., 1 (1981) 419-426.

48 Skene, J. H. P., Jacobson, R. D., Snipes, G. J., McGuire, C. B., Norden, J. J., and Freeman, J. A., A protein induced during nerve growth (GAP-43) is a major component of growth-cone membranes, Science, 233 (1986) 783-786.

49 Skene, J. H. P., Axonal growth-associated proteins, Annu. Rev. Neurosci., 12 (1989) 127-156.

50 Strand, F. L. and Kung, T. T., ACTH accelerates recovery of neuromuscular function following crushing of peripheral nerve, Peptides, 1 (1980) 135-138.

51 Strand, F. L. and Smith, C. M., LPH; ACTH; MSH and motor systems. In D. De Wied, W. H. Gispen and Tj. B. Van Wimersma Greidanus (Eds.), Neuropeptides and Behaviour, Pergamon Press, Oxford, 1986, pp. 245-272.

52 Tetzlaff, W., Zwiers, H., Lederis, K., Cassar, L. and Bisby, M. A., Axonal transport and localization of B-50/GAP-43-like immunoreactivity in regeneration of sciatic and facial nerves of the rat, J. Neurosci., 9 (1989) 1303-1313.

53 Van der Zee, C. E. E. M., Nielander, H. B., Vos, J. P., Lopes da Silva, S., Verhaagen, J., Oestreicher, A. B., Schrama, L. H., Schotman, P. and Gispen, W. H., Expression of growthassociated protein B-50/GAP-43 in dorsal root ganglia and sciatic nerve during regenerative sprouting, J. Neurosci., 9 (1989) 3505-3512.

54 Van Dongen, C. J., Zwiers, H., De Graan, P. N. E and Gispen, W. H., Modulation of the activity of purified phosphatidylinositol 4-phosphate kinase by phosphorylated and dephosphorylated B-50 protein, Biochem. Res. Commun., 128 (1985) 1219-1227.

55 Van Hooff, C. O. M., De Graan, P. N. E., Boonstra, J., Oestreicher, A. B., Schmidt-Michels, M. H. and Gispen, W. H., Nerve growth factor enhances the level of the protein kinase $\mathrm{C}$ substrate B-50 in pheochromocytoma $\mathrm{PC1} 2$ cells, Biochem. Biophys. Res. Commun., 139 (1986) 644-651.

56 Van Hooff, C. O. M., De Graan, P. N. E., Oestreicher, A. B. and Gispen, W. H., B-50 phosphorylation and polyphosphoinositide 
metabolism in nerve growth cone membranes, $J$. Neurosci., 8 (1988) 1789-1795.

57 Van Hooff, C. O. M., Holthuis, J., Oestreicher, A. B., Boonstra, J., De Graan, P. N. E. and Gispen, W. H., Nerve growth factorinduced changes in the intracellular localization of the protein kinase C substrate B-50 in pheochromocytoma PC12 cells, $J$. Cell Biol., 108 (1989) 1115-1125.

58 Van Hooff, C. O. M., Oestreicher, A. B., De Graan, P. N. E. and Gispen, W. H., Role of the growth cone in neuronal differentiation, Mol. Neurobiol., 3 (1989) 101.

59 Van Hooff, C. O. M., De Graan, P. N. E., Oestreicher, A. B. and Gispen, W. H., Muscarinic receptor activation stimulates B-50/GAP-43 phosphorylation in isolated nerve growth cones, $J$. Neurosci., (1989) in press.

60 Van Lookeren Campagne, M., Oestreicher, A. B., Van Bergen en Henegouwen, P. M. P., Verkleij, A. J. and Gispen, W. H., Ultrastructural immunocytochemical localization of the phosphoprotein B-50/GAP-43 in isolated presynaptic nerve terminals and nerve growth cones, J. Neurocytol. 18 (1989) 479-489.

61 Varon, S., Factors promoting the growth of the nervous system. In Discussions in Neurosciences, FESN II, 1985, pp. 1-62.

62 Verhaagen, J., Van Hoof, C. O. M., Edwards, P. M., De Graan, P. N. E., Oestreicher, A. B., Schotman, P., Jennekens, F. G. I. and Gispen, W. H., The kinase C substrate protein B-50 and axonal regeneration, Brain Res. Bull., 17 (1986) 737-741.

63 Verhaagen, J., Edwards, P. M., Jennekens, F. G. I., Schotman, P. and Gispen, W. H., Early effects of an ACTH4-9 analog (Org. 2766) on regenerative sprouting demonstrated by the use of neurofilament binding antibodies isolated from a serum raised by $\alpha$-MSH immunization, Brain Res., 404 (1987) 142-150.

64 Verhaagen, J., Oestreicher, A. B., Edwards, P. M., Veldman, H., Jennekens, F. G. I. and Gispen, W. H., Light and electron microscopical study of phosphoprotein B-50 following denervation and reinnervation of the rat soleus muscle, J. Neurosci., 8 (1988) 1759-1766.

65 Verhaagen, J., Oestreicher, A. B., Grillo, M., Nielander, H., Schotman, P., Gispen, W. H. and Margolis, F. L., B-50/GAP-43 in the regenerating primary olfactory pathway, Soc. Neurosci. Abstracts, 14 (1988) 802.

66 Verhaagen, J., Oestreicher, A. B., Gispen, W. H. and Margolis, F. L., The expression of the growth-associated protein B-50/GAP-43 in the olfactory system of neonatal and adult rats, J. Neurosci., 9 (1989) 683-691.

67 Vitković, L., Steisslinger, H. W., Aloyo, V. J. and Mersel, M., The 43-kDa neuronal growth-associated protein (GAP-43) is present in plasma membranes of rat astrocytes, Proc. Natl. Acad. Sci. U.S.A., 85 (1988) 8296-8300.

68 Wiegant, V. M., Zwiers, H., Schotman, P. and Gispen, W. H., Endogenous phosphorylation of rat brain synaptosomal plasma membranes in vitro: some methodological aspects, Neurochem. Res., 3 (1978) 443-463.

69 Zwiers, H., Veldhuis, H. D., Schotman, P. and Gispen, W. H., Cyclic nucleotides, and brain protein phosphorylation in vitro, Neurochem. Res., 1 (1976) 669-677.

70 Zwiers, H., Wiegant, V. M., Schotman, P. and Gispen, W. H., ACTH-induced inhibition of endogenous rat brain protein phosphorylation in vitro: structure activity study, Neurochem. Res., 3 (1978) 455-463.

71 Zwiers, H., Tonnaer, J., Wiegant, V. M., Schotman, P. and Gispen, W. H., ACTH-sensitive protein kinase from rat brain membranes, J. Neurochem., 33 (1979) 247-256.

72 Zwiers, H., Schotman, P. and Gispen, W. H., Purification and some characteristics of an ACTH-sensitive protein kinase and its substrate protein in rat brain membranes, J. Neurochem., 34 (1980) 1689-1699. 